\title{
Performance evaluation of furrow irrigation water management practice under Wonji Shoa Sugar Estate condition, in Central Ethiopia
}

\author{
Belay Yadeta $^{1 *} \mathbb{0}$, Mekonen Ayana ${ }^{1}$, Muluneh Yitayew ${ }^{2}$ and Tilahun Hordofa ${ }^{3}$
}

\author{
${ }^{*}$ Correspondence: \\ belayad@gmail.com \\ ${ }^{1}$ Department of Water \\ Resource Engineering, \\ Adama Science \\ and Technology University, \\ Adama, Ethiopia \\ Full list of author information \\ is available at the end of the \\ article
}

\begin{abstract}
Wonji Shoa Sugar Estate (WSSE) is one of the large-scale irrigation schemes in Ethiopia which was established in 1951. The aim of this study was to evaluate the performance of current furrow irrigation water management practices of WSSE. Performance evaluation of the current furrow irrigation was evaluated based on field experiment and the WinSRFR model. For this purpose, ten fields were selected from commonly used furrow lengths (32, 48, and $64 \mathrm{~m})$. Application efficiency, distribution uniformity, and deep percolation performance indicators were used for evaluation. The performance of furrow irrigation showed poor performance, and as an improvement option, inflow rate and cutoff time were altered keeping furrow geometry constant. Advance and recession times for all furrow lengths were recorded and simulated using the WinSRFR model to obtain an accurate cutoff time of irrigation. The result obtained showed that the time allocated for all furrow lengths was not accurately determined. As an improvement option, both inflow rate and cutoff time changed and the performance of furrow irrigation significantly improved. By changing those decision variables, application efficacy and deep percolation performance indicators were significantly improved but distribution uniformity was not changed. In almost all statistical indices used, predicted performances by model were better than computed values in the existing situation. From the current result, it can be concluded that the inflow rate and cutoff time should be changed to attain good performance and increase furrow irrigation efficiency.
\end{abstract}

\section{Highlights}

Performance of current furrow irrigation under Wonji Shoa sugar Estate was evaluated. For the evaluation purposes, different performance indicators were used from the measured data and the result was simulated using WinSRFR model.

The performance of existing furrow irrigation practices was showed poor performances Based on the result obtained from the existing furrow irrigation performance, the improvement options were proposed and evaluated.

Keywords: Cutoff time, Furrow irrigation, Performance evaluation, WinSRFR, Simulation, Water management, Wonji Shoa Sugar Estate 


\section{Introduction}

Irrigation is an artificial application of water to crops by using gravity or pressure to convey water from the source to the field that is required by the crop to fulfill soil moisture deficit in the crop root zone. There are three major categories of irrigation systems which include surface irrigation, subsurface irrigation, and pressurized irrigation system (Tadele, 2019). Surface irrigation is the most commonly used and oldest type of irrigation that transports water from the source to the irrigated field via gravitational forces [9]. In many developing countries, surface irrigation is widely used because of its low cost and energy requirement as compared to subsurface and pressurized irrigation systems (sprinkler and drip irrigation systems) which are usually more efficient than surface irrigation [11]. From the surface irrigation methods, furrow irrigation is mostly used from small- to large-scale irrigation systems. But if not well designed and operated, furrow irrigation can be ineffective due to the complexity of the interactions between field design, soil infiltration characteristics, and irrigation water management practices. Maintaining efficiency and effective utilization of irrigation water on large-scale irrigation at an acceptable level is the major challenge in the management of irrigation systems. Most of the time, poor performance of the furrow irrigation system resulted from incorrect dimensioning and inappropriate design furrow system [7].

Evaluation of the furrow irrigation performance for appropriate irrigation water management practices is required to overcome the losses of excess water, water stress on the crop, and its adverse effects. Performance evaluation is the systematic analysis of an irrigation system or management based on measurements taken under field conditions and practices normally used and comparing the same with an ideal one. Traditionally, irrigation assessment is conducted to evaluate the performance of existing irrigation systems. A full irrigation evaluation involves an assessment of the water source characteristics, pumping, distribution system, storage system, and field application systems. However, assessments are also conducted on several components of farm irrigation systems. The performance of an irrigation system at the field scale depends on several design variables, management variables, and system variables. In general, a set of indicators are used for evaluating the performance of an irrigation scheme. The irrigation performance indicators are classified as engineering, field water use, crop and water productivity, and socioeconomic indicators (Adane, 2020). The performance of furrow irrigation can be enhanced through proper designing based on soil, crop, topography, size, and shape of the irrigated area that affect its performance [19], because furrow irrigation system performance is influenced by various design elements. Many studies have demonstrated that improving irrigation management and field design can greatly enhance irrigation performance [2].

Nowadays, models are increasingly used to optimize furrow irrigation decision variables. The most common models used in surface irrigation systems are fully hydrodynamic, zero inertia, kinematic, and volume balance models [20]. Fully hydrodynamic models use the most general form of the Saint-Venant equations, which are the nonlinear partial differential functions that characterize the unsteady, gradually varied flow of water in a furrow. Zero inertia models are based on the understanding that flow velocities encountered in surface irrigation are very small and changes in velocity with respect to time and space are virtually non-existent. Kinematic wave models 
assume that flow in the irrigation channel is all at a fixed depth. In the kinematic wave models, the depth gradient of the flow and inertial terms of the momentum is very small and neglected. The volume, balance model applied primarily onto the advance phase and the momentum equation was completely neglected [6, 20]. Furrow irrigation systems should be designed in such a way as to ensure an adequate and uniform water application over the fields and to minimize the potential water losses. Many researchers in this field have engaged in optimizing the design of furrow irrigation systems to improve their performance $[1,7,15]$.

The performance evaluation of the furrow irrigation method can be undertaken to know how well the irrigation meets the water requirements and how well the applied water is distributed throughout the furrow run. The main purpose of furrow irrigation performance evaluation is to achieve efficient and effective use of irrigation water applied to the fields. Because, poor design and lack of suitable criteria for irrigation systems are generally responsible for uneven irrigation application leading to wastage of water, waterlogging, and salinity problems especially in surface irrigation systems (Eslamian et al., 2017)

There are several conditions imposed by the researchers to carry out performance evaluation of irrigation schemes and some of these are:

- When something is wrongly undertaken but the factors which cause it is not clearly known, which requires finding to know what are the causes of this.

- When it required to know whether the existing situation is in good condition or requires some improvement.

- When a researcher seeks to understand the detailed workings of irrigation in order to draw generalized inferences about the performance of the irrigation scheme.

The performance evaluation of the existing surface irrigation system is a key whether further improvement of the irrigation system is required or not based on the current performances. The performance evaluation of an existing irrigation system can be conducted by different performance indicators. On a scientific basis, the properties of performance indicators should be based on an empirically quantified, statistically tested fundamental model of that part of the irrigation [2].

In the case of Ethiopia, the Wonji Shoa Sugar Estate is one of the large-scale irrigation systems under production dominantly by furrow irrigation for more than half of a century and requires evaluation of its irrigation performance. Evaluation of the irrigation performance for proper irrigation water management practices at Wonji Shoa sugarcane production is very important because the Wonji Shoa Sugar Estate is one of the major sugar producers in the country. In line with this, the performance of existing furrow irrigation under the Wonji Shoa Sugar Estate was evaluated. The result obtained from the selected field showed poor performance of the existing furrow irrigation system. Based on this, improvement options were undertaken. An observational field experiment was conducted to evaluate the improvement option proposed based on ten selected fields using commonly used furrow lengths during three irrigation events. Therefore, the main purpose of this study was to evaluate the 
performance of existing furrow irrigation practices and develop improvement options for better irrigation water management practices under field conditions.

\section{Methods}

\section{Description of the study area}

The Wonji Shoa Sugar Estate (WSSE) is located in the South East Shoa Zone of Oromia Regional State, at a distance of $110 \mathrm{~km}$ from Addis Ababa, the capital city of Ethiopia. Geographically, it is situated at $8^{\circ} 21^{\prime}-8^{\circ} 29^{\prime} \mathrm{N}$ and $39^{\circ} 12^{\prime}-39^{\circ} 18^{\prime} \mathrm{E}$ and altitude of 1223 to $1550 \mathrm{~m}$ above MSL (Fig. 1). The area is characterized by gentle and regular topography making it most suitable for irrigation. Sugarcane is grown in the area, mostly as a monoculture. The climate of the area is characterized as semi-arid with the main rainy season during the months of June to September. The rainfall of the area is erratic both in quantity and distribution. The area receives a mean annual rainfall of $831 \mathrm{~mm}$ with mean annual maximum and minimum temperature of 27 and $15{ }^{\circ} \mathrm{C}$ respectively. The soil of the area varies from sandy loam to heavy clay types.

The Estate is the first commercial large-scale irrigation scheme in Ethiopia and was established in 1951 at Wonji by Netherland's Hender Verneering Amsterdam (H.V.A.) Company private investors and the Ethiopian government. When the factory started production in 1954, its initial production was 140 tons/year (WSSF, 2018). The two factories known by the name Wonji and Shoa sugar factories altogether had the capacity of producing 75,000 tons of sugar per year till recent time (prior to the completion of the new Wonji Shoa Sugar Factory at Dodota site far apart in the old factories). After serving for more than half a century and getting obsolete, the two factories viz. Wonji and Shoa sugar factories were closed in 2011 and 2012 respectively. Replacing these pioneer factories, the new and modern factory had started production in 2013 with higher production capacity. Currently, the WSSE sugarcane plantation covers and irrigated area

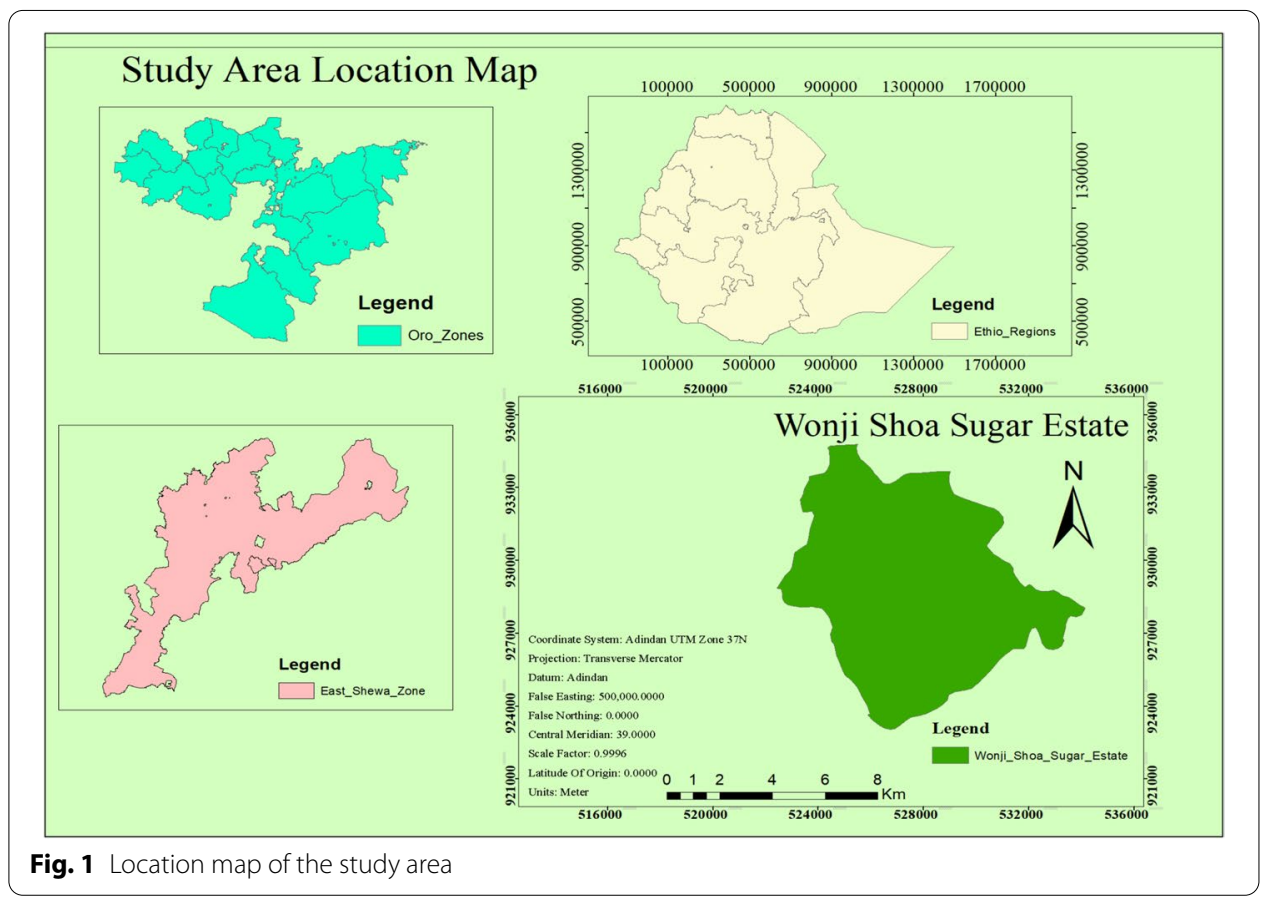


of 12,000 ha of which 5,000 ha is managed by the Estate itself and 7000 ha is managed by out-growers. The irrigation water source is the Awash River. The Wonji Shoa Sugar Estate location map is presented in Fig. 1.

\section{Experimental design}

This study design includes experimental and observational types of research to obtain the required data for the evaluation of the existing furrow irrigation under the WonjiShoa condition.

\section{Field selection}

To collect the required data, ten fields were selected with three different furrow lengths commonly used in the area $(32,48$, and $64 \mathrm{~m})$. The furrow width is common for all furrow lengths which is $1.45 \mathrm{~m}$. Those fields were selected purposively based on their location difference in all directions by considering the soil type and furrow lengths. Even if these furrow lengths are commonly used in the study area, currently, furrow length $32 \mathrm{~m}$ is more dominantly used in all types of soils and furrow length $48 \mathrm{~m}$ is rarely used. But furrow length $64 \mathrm{~m}$ became obsolete and was used only in ratoon cane fields during the study period (2019 to 2020). By considering those conditions, ten fields were purposely selected from the three furrow lengths. The field selections were based on the dominantly used furrow lengths in the sugarcane fields. Accordingly, five fields with furrow length $32 \mathrm{~m}$, three fields with furrow length $48 \mathrm{~m}$, and two fields with a 64-m furrow length were selected.

\section{Water application methods}

Irrigation water was applied to the field by the furrow irrigation system. During the irrigation application, the water diverted to the field ditches was controlled using gates at the outlets of the secondary canals. The inflow rate applied to each furrow was 4.7 1/s under the existing furrow irrigation practices. This inflow rate was applied to each field and three irrigation events were considered for data collection. The three irrigation events were similarly considered for all furrow lengths (irrigation event one for furrow lengths 32,48 , and $64 \mathrm{~m}$; irrigation event two for furrow lengths 32,48 , and $64 \mathrm{~m}$; and irrigation event three for furrow lengths 32,48 , and $64 \mathrm{~m}$ ). For each selected field, five furrow lengths were selected for data collection at one time for all furrow lengths. At one irrigation event, 50 furrows were considered which was similar to all irrigation events. The data collected from five furrows was averaged out that was presented as one data at one irrigation event for each furrow length.

\section{Data collection methods}

Primary and secondary data were collected to evaluate the performance of the existing furrow irrigation practices. Based on the performance of the existing furrow irrigation practices, improvement options were proposed and the performance also evaluated again during the study periods. The primary data was collected from each selected field during three consecutive irrigation events which include furrow geometry, irrigation time, and soil moisture analysis. For furrow geometry, furrow length and furrow width (top, middle, and bottom width) were measured at 
field conditions using a meter tape. The maximum flow depth was measured using a ruler during each irrigation event. Advance time (time taken from the entrance of irrigation to the furrow to some specified points), cutoff time (time taken from the starting of irrigation to inflow cutoff), and recession time (time taken from the inflow cutoff to all water ponded on the field fully infiltrated) were recorded using a stopwatch. The advance and recession times were recorded at 16-m intervals for all fields and furrow lengths, while the secondary data were irrigation history and cane types.

\section{Soil sample collection and analyses}

Soil samples were collected at two soil depths $(0-30$ and 30-60 cm) of representative fields for the purpose of determining bulk densities, textures, and soil moisture content. The soil sample was analyzed in the laboratory at Wonji Shoa Sugar Research and Development Center. The soil moisture content at field capacity and permanent wilting point of the selected fields were taken from the center because it was done very recently. The soil parameters were analyzed following standard laboratory procedures and manual [4].

The soil sample was taken at 16-m intervals along the furrow for all fields from the specified depths of sampling and soil moisture was determined using gravimetric methods. The depth is believed to cover the effective root depth of the sugarcane. The soil samples were taken from inside furrow before and after irrigation water application from 2 to 3 days based on the soil types. The soil samples were taken by a soil core sampler and then the soil wet weight was weighted using a movable sensitive balance immediately after the sample was taken. The samples were then oven-dried at $105{ }^{\circ} \mathrm{C}$ for 24 $\mathrm{h}$. The dried weight of the soil sample was again weighted to calculate the gravimetric moisture content using (Eq. 1) [4].

$$
\mathrm{W}_{\theta}=\left(\frac{\mathrm{W}_{\mathrm{w}}-\mathrm{W}_{\mathrm{d}}}{\mathrm{W}_{\mathrm{d}}}\right) \times \text { As } \times 100
$$

where $W_{\theta}=$ gravimetric soil moisture content (\% volume bases), $W_{\mathrm{w}}=$ wet weight of the soil (g), $W_{\mathrm{d}}=$ dry weight of the soil (g), $A_{\mathrm{s}}=$ apparent specific gravity ( - )

The water holding capacity of the soil was analyzed by computing the total available water and readily available water using (Eqs. 2 and 3) [8].

$$
\mathrm{TAW}=1000\left(\theta_{\mathrm{FC}}-\theta_{\mathrm{PWP}}\right) \times D_{i}
$$

$$
\mathrm{RAW}=\rho \times \mathrm{TAW}
$$

where TAW $=$ the total available soil water in the root zone $(\mathrm{mm}), \theta_{\mathrm{FC}}=$ the soil water content at field capacity $\left(\mathrm{m}^{3} / \mathrm{m}^{3}\right), \theta_{\text {PWP }}=$ the soil, water content at wilting point $\left(\mathrm{m}^{3} /\right.$ $\left.\mathrm{m}^{3}\right), D_{i}=$ the rooting depth $(\mathrm{m}), \rho=$ soil moisture depletion fraction.

The required depth of irrigation, depth of water stored in the soil profile of the root zone $\left(D_{\mathrm{s}}\right)$ and the total depth of water applied to the field $\left(D_{\mathrm{a}}\right)$ and the total amount of water deep percolated were calculated using (Eqs. 4, 5, 6). 


$$
Z_{\mathrm{req}}=\sum_{i=1}^{n} 10\left(\theta_{\mathrm{FC}}-\theta_{\mathrm{mi}}\right) \times A S_{i} \times D_{i}
$$

where $Z_{\text {req }}=$ amount of water required to fill the root zone to field capacity $(\mathrm{mm})$, $\theta_{\mathrm{FC}}=$ soil moisture content at field capacity (\%), $\theta_{\mathrm{mi}}=$ present soil moisture content (\%), $A S_{i}=$ apparent specific gravity of the soil (unit less), $D_{i}=$ effective root depth (m), $n=$ number of sampling depth in the root zones.

$$
\begin{aligned}
& D_{\mathrm{s}}=\sum_{i=1}^{n} \frac{\left(M_{a i}-M_{b i}\right)}{100} \times A S_{i} \times D_{i} \\
& D_{\mathrm{a}}=\frac{\bar{Q} \times \Delta t}{A}
\end{aligned}
$$

where $\mathrm{M}_{a i}=$ Moisture content of $i$ th layer of the soil after irrigation on a dry weight basis (\%), $\mathrm{M}_{b i}=$ Moisture content of $i$ th layer of soil before irrigation on dry weight basis (\%), $\bar{Q}=$ average discharge to furrow during the irrigation $\left(\mathrm{m}^{3} / \mathrm{s}\right), \Delta t=$ duration of the irrigation (s), $A=$ furrow irrigated area $\left(\mathrm{m}^{2}\right)$

The depth of water percolating below the root zone is the amount of water infiltrated minus the water extracted by the plant roots to meet its evaporation demands. Or this means deep percolation is the difference in the amount of water applied to satisfy the crop water requirement and the amount of water excess applied or lost before the crop conception. This is computed using the soil water balance analysis. This depth of water can be computed experimentally in different methods like lysimeter but for the current study it was computed from the soil moisture analysis (Eq. 7)

$$
D_{\mathrm{p}}=\theta_{\mathrm{i}}+I_{\mathrm{d}}+R_{\mathrm{d}}-\theta_{\mathrm{FC}}-\mathrm{ET}
$$

where $D_{\mathrm{p}}=$ depth of water deep percolated, $\theta_{i}=$ initial soil moisture content, $I_{\mathrm{d}}=$ depth of irrigation applied, $R_{d}=$ depth of available rainfall, $\theta_{\mathrm{FC}}=$ soil moisture content at field capacity and ET $=$ evapotranspiration.

The soil infiltration function is one of the most important parameters in the surface irrigation system performance evaluation. There was a different infiltration function developed so far that was used based on some preferences of the users according to available input data and required outputs. The infiltration function is empirically determined to yield the relationship between the infiltrated water and the opportunity time (the time during which the water contacts the soil). One of the empirical models for infiltration is Kostiakov's infiltration model (Kostiakov, 1932), which is derived using the data observed under either field or laboratory conditions. The power type Kostiakov function is the most widely accepted to describe the infiltration characteristics (Eq. 8).

$$
\mathrm{Z}=K t^{a}
$$

$Z=$ infiltrated water $\mathrm{m} 3 / \mathrm{m} ; k, a=$ empirical parameters; $t=$ intake opportunity time, $\min$

The zero inertia model is based on the understanding that flow velocities encountered in surface irrigation with very small and changes in velocity with respect to time and 
space are virtually non-existent. Under most surface irrigation conditions, inertial terms in the Saint-Venant equations are negligible when compared to the force terms (heat and friction). The zero inertia model is a simplified form of the fully hydrodynamic model without the acceleration and inertia terms which is given by Eq. 9 [21].

$$
\frac{\delta y}{\delta x}=S_{0}-S_{\mathrm{f}}
$$

where $y=$ depth of flow $(\mathrm{m}), x=$ distance along the field length $(\mathrm{m}), S_{0}=$ longitudinal slope of the field $(\mathrm{m} / \mathrm{m}), S_{\mathrm{F}}=$ slope of energy grade line (friction slope) $(\mathrm{m} / \mathrm{m})$,

\section{Performance evaluation of furrow irrigation}

The performance evaluation of irrigation gives an insight into how well the irrigation meets the water requirements and the applied water is distributed uniformly throughout the field. The most common performance evaluation criteria in furrow irrigation are application efficiency, deep percolation ratio, tailwater ratio, distribution uniformity, and water requirement efficiency. But for the performance evaluation of close-ended furrow irrigation conditions, application efficiency, deep percolation, and distribution uniformity are commonly used. In general, to improve irrigation performance, mathematical models of the surface irrigation processes have been developed in the last decades. Developed models consider several variables, including field geometries, slope, hydraulic roughness, furrow discharges, and irrigation time. The interaction among these variables determines the advance times, recession times, and infiltrated water depth, which in turn influence performance indicators such as application efficiency and uniformity of water distribution along the furrow. Those selected parameters were evaluated by measuring the required data from the field and simulated using the WinSRFR model. Those parameters were mathematically determined using Eqs. 10, 11, 12 [13, 14].

$$
\begin{aligned}
& \mathrm{AE}=\frac{D_{\mathrm{S}}}{D_{\mathrm{a}}} \times 100 \\
& \mathrm{DU}=\frac{D_{\text {min }}}{D_{\mathrm{a}}} \times 100 \\
& \mathrm{DP}=\frac{D_{\mathrm{p}}}{D_{\text {aver }}} \times 100
\end{aligned}
$$

where $D_{\mathrm{s}}=$ depth of soil moisture stored in the root zone $(\mathrm{mm}), D_{\mathrm{a}}=$ total depth applied to the furrow $(\mathrm{mm}), D_{\min }=$ minimum depth of water infiltrated in the field $(\mathrm{mm}), D_{\text {aver }}=$ mean of depths infiltrated over the furrow length $(\mathrm{mm})$.

To improve the performance of the furrow irrigation, the three main parameters considered were furrow geometry, cutoff time, and inflow rate. Since the performance evaluation was undertaken on the existing furrow situation, it was very difficult to change the furrow geometry. But in this study, to improve the performance of the furrow irrigation, cutoff time and inflow rate were alternatively tests. The procedure was as follows:

Step one: All parameters were used as they were measured from the field under current irrigation practice to evaluate the performance of furrow irrigation. 
Step two: Inflow rate was varied while the other parameters (furrow geometry and cutoff time) were kept constant and the performance of the furrow irrigation was evaluated.

Step three: Cutoff time was varied while the other parameters (furrow geometry and inflow rate) were kept constant and similarly the performance of the furrow irrigation was evaluated.

Step four: Furrow geometry was taken as a constant and both inflow rate and cutoff time were varied in which similar to the other steps the performance of the furrow irrigation again evaluated.

The optimization performance of furrow irrigation was computed using Eq. 13 and the maximum values of the optimized result were used as the decision variables to improve the performance of the irrigation $[13,14]$.

$$
O P=(\alpha \times E a)+(\beta \times D U)-(\gamma \times D P)
$$

where the correction factors for the parameters $\alpha=\beta=\gamma=0.33$

\section{Input data for WinSRFR model}

The functionality and organization of WinSRFR were defined based on the analytical process typically followed in assessing and improving the hydraulic performance of surface irrigation systems. All required data for the WinSRFR 4.1.3 model was collected from the field with a close-ended furrow irrigation system. The input data required for the WinSRFR model were the required depth of irrigation, furrow geometry, advance, cutoff, and recession time of irrigation. These data were collected from the selected fields. The soil samples were taken from the field and analyzed in the soil laboratory to determine the required depth of irrigation. The furrow geometry was measured at constant intervals along the furrow. The advance, cutoff, and recession times were recorded during irrigation events. There are several efficiency terms which are used to evaluate irrigation system performance. But for this study, application efficiency, distribution uniformity, and deep percolation were used. The major input parameters for the simulations were presented in Table 1.

\section{Statistical indices used to evaluate the model performance}

Measured and simulated performance indicators were evaluated using the statistical indices. To test the goodness of fit between measured and simulated values, different statistical indices were used [13, 14].

\section{Coefficient of determination $\left(R^{2}\right)$}

The coefficient of determination is used to measure the model's goodness of fit. In the WinSRFR model, $R^{2}$ is an indicator of the efficiency of the model in comparing the measured values with the simulated values. It explains the amount of variance explained by the model in comparison to the measured values (Eq. 14). 
Table 1 Input parameters for the WinSRFR simulation model



where $n=$ number of observations, $M_{i}=i$ th value of the measurement, $S_{i}=i$ th value of the simulated, $\bar{M}=$ mean of the measured values, $\bar{S}=$ mean of values simulated

\section{Root mean square error}

Root mean square error is a measure of the overall deviation between measured and simulated values. The root mean square error has a minimum value of 0 and the values closer to 0 indicate the better model performance (Eq. 15).

$$
\operatorname{RMSE}=\sqrt{\frac{\sum_{i=1}^{n}\left(S_{i}-M\right)^{2}}{n}}
$$

Index of agreement (d)

Index of agreement is another statistical index used to measure the model efficiency. The value of $d$ varies from $-\infty$ to +1 . The closer the value to +1 indicates the simulated values are better than the measured values (Eq. 16).

$$
d=1-\frac{\sum_{i=1}^{n}\left(M_{i}-S_{i}\right)^{2}}{\left(\sum_{i=1}^{n}\left|S_{i}-\bar{S}\right|+\left|M_{i}-M\right|\right)^{2}}
$$

\section{Results and discussions}

\section{Selected soil properties}

The soil samples taken from each field were analyzed at the Wonji Shoa Sugar Research and Development Center. As the result obtained indicated, the average soil bulk density 
of the fields was ranging from 1.49 to 1.60 for the upper depth $(0-30 \mathrm{~cm})$ and 1.59 to $1.70 \mathrm{~g} / \mathrm{cm} 3$ for lower depth $(30-60 \mathrm{~cm})$ but the recommended soil bulk density of the Wonji Shoa ranges from 1.5 to $1.7 \mathrm{~g} / \mathrm{cm}^{3}$ from $0-30$ - to $30-60-\mathrm{cm}$ depth respectively. The average soil moisture content was determined over the considered depths during each irrigation event and found to be 40.49 to $42.77 \%$ in the upper depth and 41.82 to 45.03\% in the lower depth respectively (Table 2).

The result obtained from the selected soil parameters revealed the soil parameters analyzed were within the range of the analysis obtained in the previous study by the center (Table 2). But the bulk density in upper depth indicated a little variation greater than the previous study by the center and this may be due to the compaction of the soil by agronomic operation and repeated irrigation.

\section{Advance and recession times}

For each furrow length considered, the advanced and recession time was measured during all the irrigation events. The measured advanced and recession time was simulated using the WinSRFR model. Whether the time allotted for irrigation is greater than or less than the required time for each furrow length during three irrigation events was evaluated. The results of the measured and simulated irrigation time are presented in Table 3.

There was no variation between the measured advanced time during the first and third irrigation events in furrow length $32 \mathrm{~m}$. But there was significant variation in furrow lengths 48 and $64 \mathrm{~m}$ during all irrigation events. In the case of simulated advance time, there was a significant variation in all furrow lengths during all irrigation events. The variation was high in furrow lengths $32(22.03 \%)$ and $48 \mathrm{~m}(20.31 \%)$, and less in furrow length $64 \mathrm{~m}(2.12 \%)$ during the third irrigation event. This indicates when the variation is very high, the time allocated for irrigation is not accurate and less variance indicated that the allocated time for irrigation was more accurate. In the case of recession time, in all furrow lengths considered, the simulated recession time was lower than the measured recession time, which indicates irrigation water applied stagnated on the surface of the land for a long period. The variation was significant in furrow lengths 64 and 48

Table 2 Analysis of selected soil parameters for the selected fields

\begin{tabular}{|c|c|c|c|c|c|c|c|c|c|c|}
\hline \multirow[t]{2}{*}{ Field no. } & \multirow[t]{2}{*}{ Furrow length } & \multicolumn{2}{|c|}{$P_{\mathrm{d}}\left(\mathrm{g} / \mathrm{cm}^{3}\right)$} & \multirow[t]{2}{*}{ Soil texture } & \multicolumn{2}{|c|}{$\mathrm{FC}(\%)$} & \multicolumn{2}{|c|}{ PWP (\%) } & \multicolumn{2}{|c|}{ MC (\%) } \\
\hline & & $0-30$ & $30-60$ & & $0-30$ & $30-60$ & $0-30$ & $30-60$ & $0-30$ & $30-60$ \\
\hline 15 & $32 \mathrm{~m}$ & 1.53 & 1.64 & Clay & 48.50 & 51.90 & 21.60 & 22.4 & 40.29 & 41.82 \\
\hline 42 & & 1.55 & 1.64 & Silt & 49.10 & 49.70 & 28.60 & 27.20 & 41.18 & 42.87 \\
\hline 80 & & 1.54 & 1.62 & Silt & 48.50 & 51.90 & 21.60 & 22.40 & 41.15 & 42.12 \\
\hline 102 & & 1.51 & 1.60 & Silt & 49.10 & 49.70 & 28.60 & 27.20 & 40.03 & 41.09 \\
\hline 279 & & 1.55 & 1.66 & Clay & 49.10 & 49.70 & 28.60 & 27.20 & 40.72 & 44.25 \\
\hline 15 & $48 \mathrm{~m}$ & 1.60 & 1.70 & Clay & 48.50 & 51.90 & 21.60 & 22.40 & 42.77 & 43.30 \\
\hline 16 & & 1.50 & 1.62 & Clay & 50.50 & 54.90 & 24.20 & 24.40 & 44.30 & 45.02 \\
\hline 80 & & 1.55 & 1.60 & Silt & 48.50 & 51.90 & 22.40 & 21.73 & 40.59 & 43.93 \\
\hline 15 & $64 \mathrm{~m}$ & 1.50 & 1.59 & Clay & 48.88 & 51.16 & 21.98 & 22.28 & 40.41 & 42.59 \\
\hline 264 & & 1.49 & 1.61 & Silt & 48.88 & 51.16 & 21.98 & 22.28 & 41.36 & 42.68 \\
\hline
\end{tabular}

$P_{d}$ bulk density, $F C$ soil moisture content at field capacity, PWP moisture content at the permanent wilting point, $M C$ present soil moisture content, $D_{\text {app }}=$ depth of application 
Table 3 Measured and simulated irrigation time under existing irrigation practices

\begin{tabular}{|c|c|c|c|c|c|c|c|}
\hline \multirow[t]{2}{*}{ IEs } & \multirow[t]{2}{*}{$\mathrm{FL}$} & \multirow[t]{2}{*}{$\mathrm{FQ}(\mathrm{l} / \mathrm{s})$} & \multirow[t]{2}{*}{$T_{\text {co }}(\min )$} & \multicolumn{2}{|c|}{ Advance time (min) } & \multicolumn{2}{|c|}{$\begin{array}{l}\text { Recession time } \\
\text { (min) }\end{array}$} \\
\hline & & & & Meas. & Sim. & Meas. & Sim. \\
\hline \multirow[t]{3}{*}{1} & 32 & 4.7 & 9 & 10 & 8 & 37 & 33 \\
\hline & 48 & 4.7 & 15 & 17 & 14 & 58 & 39 \\
\hline & 64 & 4.7 & 25 & 28 & 23 & 68 & 47 \\
\hline \multirow[t]{3}{*}{2} & 32 & 4.7 & 9 & 16 & 15 & 54 & 39 \\
\hline & 48 & 4.7 & 15 & 19 & 17 & 60 & 42 \\
\hline & 64 & 4.7 & 25 & 28 & 26 & 57 & 41 \\
\hline \multirow[t]{3}{*}{3} & 32 & 4.7 & 9 & 10 & 7 & 38 & 37 \\
\hline & 48 & 4.7 & 15 & 17 & 12 & 58 & 43 \\
\hline & 64 & 4.7 & 25 & 29 & 28 & 61 & 47 \\
\hline
\end{tabular}

IEs consecutive irrigation events, FL furrow length, $Q$ discharge applied, $T_{c o}$ cutoff time, Meas. measured, Sim. simulated

$\mathrm{m}$ than $32 \mathrm{~m}$. The current study was similar to the study conducted by Mazarei et al. $[13,14]$ which indicates the best fit between measured and simulated was achieved for the advance phase than the recession time. Similarly, the study conducted by Ali and Mohammed [3] indicates a similar result with the current study. Also, the other study conducted by [16]) indicated low variation in advance and recession times between measured and simulated values.

\section{Performance evaluation of furrow irrigation}

Performance evaluation of furrow irrigation was done based on the measurement undertaken on selected furrows as described in the methodology section. The WinSRFR model was used to simulate the measured data whether they were best fitted or not. The results are presented in Table 4. The computed and simulated application efficiency, distribution uniformity, and deep percolation were compared across the furrow lengths considered compared to the standard ranges of recommendation for furrow irrigation [10]. The overall average values of measured and simulated application efficiency and deep percolation performance of the existing furrow irrigation practices showed poor but distribution uniformity of the irrigation was relatively good for all furrow lengths.

Table 4 Computed and simulated performance indicators for existing furrow irrigation practices

\begin{tabular}{|c|c|c|c|c|c|c|c|c|c|}
\hline \multirow[t]{2}{*}{ IEs } & \multirow[t]{2}{*}{$\mathrm{FL}(\mathrm{m})$} & \multirow[t]{2}{*}{$\mathrm{Q}(\mathrm{l} / \mathrm{s})$} & \multirow[t]{2}{*}{$T_{\mathrm{co}}(\min )$} & \multicolumn{2}{|l|}{$\mathrm{AE}(\%)$} & \multicolumn{2}{|l|}{ DU (\%) } & \multicolumn{2}{|l|}{ DP (\%) } \\
\hline & & & & Comp. & Sim. & Comp. & Sim. & Comp. & Sim. \\
\hline \multirow[t]{3}{*}{1} & 32 & 4.7 & 9 & 48.4 & 43.2 & 85.8 & 83.2 & 51.6 & 56.8 \\
\hline & 48 & 4.7 & 15 & 52.0 & 43.7 & 79.3 & 73.0 & 48.0 & 56.3 \\
\hline & 64 & 4.7 & 25 & 58.0 & 55.5 & 90.5 & 70.0 & 55.0 & 44.0 \\
\hline \multirow[t]{3}{*}{2} & 32 & 4.7 & 9 & 44.2 & 46.6 & 87.2 & 80.6 & 55.8 & 53.4 \\
\hline & 48 & 4.7 & 15 & 49.7 & 48.0 & 82.7 & 64.7 & 50.3 & 52.0 \\
\hline & 64 & 4.7 & 25 & 49.0 & 49.0 & 91.0 & 62.5 & 51.0 & 51.0 \\
\hline \multirow[t]{3}{*}{3} & 32 & 4.7 & 10 & 46.0 & 53.2 & 89.0 & 77.2 & 54.0 & 46.8 \\
\hline & 48 & 4.7 & 15 & 54.0 & 53.7 & 81.7 & 67.7 & 46.0 & 46.3 \\
\hline & 64 & 4.7 & 25 & 41.5 & 41.5 & 88.0 & 69.5 & 58.5 & 58.5 \\
\hline
\end{tabular}

Comp. computed, Sim. simulated, $A E$ application efficiency, $D U$ distribution uniformity, $D P$ deep percolation 
The performance of furrow irrigation under the current irrigation practices was poor. Application efficiency was less than the recommended values for almost all irrigation events in furrow lengths 32 and $64 \mathrm{~m}$ but furrow length $48 \mathrm{~m}$ during the first and third irrigation events and furrow length $64 \mathrm{~m}$ during the third irrigation event was within the recommended range. But relatively, furrow length $48 \mathrm{~m}$ was within the recommendation ranges for all irrigation events. However, the distribution uniformity for furrow length $48 \mathrm{~m}$ was less than the furrow lengths 32 and $64 \mathrm{~m}$ in all irrigation events. In terms of the distribution uniformity of irrigation, furrow length $64 \mathrm{~m}$ was very good followed by furrow lengths 32 and $48 \mathrm{~m}$ respectively. On the other hand, the deep percolation was greater than the recommendation ranges for furrow lengths 32 and $64 \mathrm{~m}$ but furrow length $48 \mathrm{~m}$ during all irrigation events showed within the recommendation ranges (Table 4) which indicates more amount of irrigation water lost before the crop conception.

To improve the performance of furrow irrigation, decreasing the inflow rate and increasing the cutoff time or vice versa are the main options. In line with this, for the first alternatives to improve the performance of the irrigation, the irrigation water applied was reduced by $25 \%$ from the normal irrigation water inflow rate used ( 28 1/s for six sets of furrows at one time) in the existing irrigation practices. After this reduction of inflow rate, the furrow irrigation performance was computed for all furrow lengths during all irrigation events. The computed and simulated performance indicators of the furrow irrigation after the inflow rate was reduced were improved (Table 5).

As can be seen from the results, decreasing the inflow rate of $4.7 \mathrm{l} / \mathrm{s}$ (current irrigation practices) to $3.5 \mathrm{l} / \mathrm{s}$ showed an improvement in furrow irrigation performances. From the furrow irrigation performance indicators considered, application efficiency was greatly improved by changing the inflow rate than the other performance indicators.

In the second alternative, irrigation cutoff time was changed by keeping the other variables as constant as same to the existing practices. In this scenario, the cutoff time was reduced by 2,3 , and 6 min for furrow lengths 32,48 , and 64 m respectively from the existing irrigation practices. The performance of the furrow irrigation was improved as compared to the existing furrow irrigation performance. As can be

Table 5 Computed and simulated performance indicators by changing inflow rate

\begin{tabular}{|c|c|c|c|c|c|c|c|c|c|}
\hline \multirow[t]{2}{*}{ IEs } & \multirow[t]{2}{*}{$\mathrm{FL}(\mathrm{m})$} & \multirow[t]{2}{*}{$\mathrm{Q}(\mathrm{l} / \mathrm{s})$} & \multirow[t]{2}{*}{$T_{\text {co }}(\min )$} & \multicolumn{2}{|l|}{$\mathrm{AE}(\%)$} & \multicolumn{2}{|l|}{ DU (\%) } & \multicolumn{2}{|l|}{ DP (\%) } \\
\hline & & & & Comp. & Sim. & Comp. & Sim & Comp. & Sim. \\
\hline \multirow[t]{3}{*}{1} & 32 & 3.5 & 9 & 61.0 & 44.0 & 85.8 & 81.4 & 39.0 & 56.0 \\
\hline & 48 & 3.5 & 15 & 59.0 & 57.7 & 79.3 & 63.7 & 41.0 & 42.3 \\
\hline & 64 & 3.5 & 25 & 60.0 & 59.5 & 90.5 & 51.5 & 40.0 & 40.5 \\
\hline \multirow[t]{3}{*}{2} & 32 & 3.5 & 9 & 61.0 & 62.0 & 85.8 & 74.2 & 41.0 & 38.0 \\
\hline & 48 & 3.5 & 15 & 60.0 & 57.3 & 89.7 & 57.7 & 40.7 & 42.7 \\
\hline & 64 & 3.5 & 25 & 65.5 & 64.0 & 91.0 & 49.5 & 34.5 & 36.0 \\
\hline \multirow[t]{3}{*}{3} & 32 & 3.5 & 10 & 56.8 & 62.6 & 83.0 & 71.2 & 43.2 & 37.4 \\
\hline & 48 & 3.5 & 15 & 68.3 & 69.3 & 81.7 & 56.7 & 31.7 & 30.7 \\
\hline & 64 & 3.5 & 25 & 56.0 & 56.0 & 88.0 & 59.5 & 44.0 & 44.0 \\
\hline
\end{tabular}


seen from Table 6, the irrigation performance of the furrow lengths considered was improved. As results revealed, the irrigation efficiency was improved by changing only the cutoff time and keeping the other parameters constant.

Finally, the performance of furrow irrigation was evaluated by varying both inflow rate and cutoff time. In furrow irrigation, performance can be improved by reducing the discharge rate and increasing the cutoff time or vice versa. But in relation to irrigation water resource concerns, reducing discharge rate and increasing cutoff time is more preferable. In the current study, the discharge rate was reduced from 4.7 to $3.5 \mathrm{l} / \mathrm{s}$ and increased cutoff time by 2,3 , and $6 \mathrm{~min}$ for furrow lengths 32, 48, and $64 \mathrm{~m}$ respectively. By combining those two decision variables, the performance of furrow irrigation in all furrow length during the three irrigation events were improved. The computed maximum and minimum optimized values were 47.69 and $38.21 \%$ recorded from furrow lengths 64 and $32 \mathrm{~m}$ during the first and third irrigation events respectively. The overall computed optimized values were 39.82, 44.81, and $46.26 \%$ for furrow lengths 32,48 , and $64 \mathrm{~m}$ respectively (Table 7 ).

Table 6 Computed and simulated performance indicators by changing cutoff time

\begin{tabular}{|c|c|c|c|c|c|c|c|c|c|}
\hline \multirow[t]{2}{*}{ IEs } & \multirow[t]{2}{*}{$\mathrm{FL}(\mathrm{m})$} & \multirow[t]{2}{*}{$\mathrm{Q}(\mathrm{l} / \mathrm{s})$} & \multirow[t]{2}{*}{$T_{\text {co }}(\min )$} & \multicolumn{2}{|l|}{$\mathrm{AE}(\%)$} & \multicolumn{2}{|l|}{ DU (\%) } & \multicolumn{2}{|l|}{ DP (\%) } \\
\hline & & & & Comp. & Sim. & Comp. & Sim & Comp. & Sim. \\
\hline \multirow[t]{3}{*}{1} & 32 & 4.7 & 7 & 66.0 & 67.6 & 85.8 & 68.0 & 34.0 & 32.4 \\
\hline & 48 & 4.7 & 12 & 68.3 & 69.3 & 81.7 & 56.7 & 31.7 & 30.7 \\
\hline & 64 & 4.7 & 19 & 56.0 & 56.0 & 88.0 & 59.5 & 44.0 & 44.0 \\
\hline \multirow[t]{3}{*}{2} & 32 & 4.7 & 7 & 61.0 & 65.2 & 87.2 & 68.8 & 33.0 & 36.8 \\
\hline & 48 & 4.7 & 12 & 68.3 & 68.7 & 82.7 & 51.3 & 31.7 & 31.3 \\
\hline & 64 & 4.7 & 19 & 69.5 & 71.5 & 91.0 & 41.5 & 30.5 & 28.5 \\
\hline \multirow[t]{3}{*}{3} & 32 & 4.7 & 7 & 63.0 & 66.4 & 89.0 & 67.2 & 39.0 & 33.6 \\
\hline & 48 & 4.7 & 12 & 71.0 & 70.7 & 81.7 & 50.7 & 29.0 & 29.3 \\
\hline & 64 & 4.7 & 19 & 64.5 & 63.5 & 88.0 & 53.5 & 35.5 & 36.5 \\
\hline
\end{tabular}

Table 7 Computed and simulated performance evaluation by changing discharge and cutoff time

\begin{tabular}{|c|c|c|c|c|c|c|c|c|c|c|c|}
\hline \multirow[t]{2}{*}{ IEs } & \multirow[t]{2}{*}{$\mathrm{FL}(\mathrm{m})$} & \multirow[t]{2}{*}{$\mathrm{Q}(\mathrm{l} / \mathrm{s})$} & \multirow[t]{2}{*}{$T_{\mathrm{co}}(\mathrm{min})$} & \multicolumn{2}{|l|}{$A E(\%)$} & \multicolumn{2}{|l|}{ DU (\%) } & \multicolumn{2}{|l|}{ DP (\%) } & \multicolumn{2}{|l|}{ OP (\%) } \\
\hline & & & & Comp. & Sim. & Comp. & Sim & Comp. & Sim. & Comp. & Sim. \\
\hline \multirow[t]{3}{*}{1} & 32 & 4.7 & 9 & 68.2 & 67.6 & 85.8 & 68.4 & 31.8 & 32.4 & 40.33 & 34.19 \\
\hline & 48 & 4.7 & 15 & 77 & 77.7 & 81 & 49.7 & 23 & 22.3 & 44.55 & 34.68 \\
\hline & 64 & 4.7 & 25 & 77 & 76.5 & 90.5 & 34.5 & 23 & 23.5 & 47.69 & 28.88 \\
\hline \multirow[t]{3}{*}{2} & 32 & 4.7 & 9 & 68.4 & 68.6 & 87.2 & 69.8 & 31.6 & 32.4 & 40.92 & 34.98 \\
\hline & 48 & 4.7 & 15 & 76.3 & 78 & 82.7 & 42.7 & 23.7 & 22 & 44.65 & 32.57 \\
\hline & 64 & 4.7 & 25 & 74.5 & 76.5 & 91 & 35.5 & 30.5 & 23.5 & 44.55 & 29.21 \\
\hline \multirow[t]{3}{*}{3} & 32 & 4.7 & 10 & 63.4 & 62.2 & 89 & 67.8 & 36.6 & 37.8 & 38.21 & 30.43 \\
\hline & 48 & 4.7 & 15 & 77.7 & 74.7 & 81.7 & 54 & 22.3 & 25.3 & 45.24 & 34.12 \\
\hline & 64 & 4.7 & 25 & 76.5 & 78.5 & 88 & 38 & 23.5 & 21.5 & 46.53 & 31.35 \\
\hline
\end{tabular}




\section{Discussion of the results Application efficiency}

For well-designed and managed furrow irrigation, the standard ranges of furrow irrigation application efficiency recommended is $50-70 \%$ but can be more based on soil types and management practices (Griffiths, 2007). The performance evaluation of three furrow lengths for the three irrigation events was evaluated based on the existing irrigation practices that showed poor performance. As an improvement option, changing the decision variables alternatively and combining the changed decision variables together were evaluated. The maximum and minimum application efficiency obtained from the existing furrow irrigation practices were 58 and $41.5 \%$ from furrow length $64 \mathrm{~m}$ during the first and third irrigation events. When the average computed application efficiencies of those three furrow lengths in the overall three irrigation events at the existing practices were compared, furrow lengths of 48 and $64 \mathrm{~m}$ were performing better with an application efficiency of 51.9 and $49.5 \%$ respectively. Similarly, in the simulated values using the WinSRFR model, the same furrow lengths perform better with 48.5 and $48.7 \%$ application efficiency respectively. From the current study findings, it can be concluded that based on the average computed values, only furrow length $48 \mathrm{~m}$ fulfill the recommendation for furrow irrigation application efficiency. This indicated that the performance of the existing furrow irrigation based on application efficiency showed poor performance.

When the inflow rate decision variable changed, the computed maximum and minimum application efficiency obtained were 68.3 and 56.0\% from furrow lengths 48 and 32 $\mathrm{m}$ during the third and second irrigation events. The result obtained indicated by changing only the inflow rate decision variable, the application efficiency of furrow irrigation was improved. Similarly, from the simulated values using the model, the maximum and minimum application efficiencies obtained were 69.3 and $44.0 \%$ from furrow lengths 48 and $32 \mathrm{~m}$ during third and first irrigation events respectively. This indicated when the inflow rate was reduced, more application efficiency improvement was obtained from furrow length $48 \mathrm{~m}$.

When cutoff time changed by keeping the other variables constant, the computed maximum and minimum application efficiencies obtained were 71.0 and $56 \%$ from furrow lengths 48 and $64 \mathrm{~m}$ during the third and first irrigation events. From the simulated values using the WinSRFR model, the maximum and minimum application efficiency obtained were 71.5 and 56\% from furrow lengths 48 and $64 \mathrm{~m}$ during the second and first irrigation event respectively. By changing this decision variable, the application efficiency of all furrow lengths during all irrigation events was within the range of recommendation.

When both discharge and cutoff time changed by keeping the other variables constant, the computed maximum and minimum application efficiencies obtained were 77.7 and $63.4 \%$ from furrow lengths 48 and $32 \mathrm{~m}$ during the third irrigation event. From the simulated values using the WinSRFR model, the maximum and minimum application efficiencies obtained were 78.5 and $62.2 \%$ from furrow lengths 64 and $32 \mathrm{~m}$ during the third irrigation event respectively. By reducing the inflow and increasing the irrigation cutoff time, the furrow irrigation application efficiency was improved by $25.4 \%$ from the existing irrigation practices. The application efficiency was compared in all scenarios for all furrow lengths during the three irrigation events were presented in Fig. 2. 


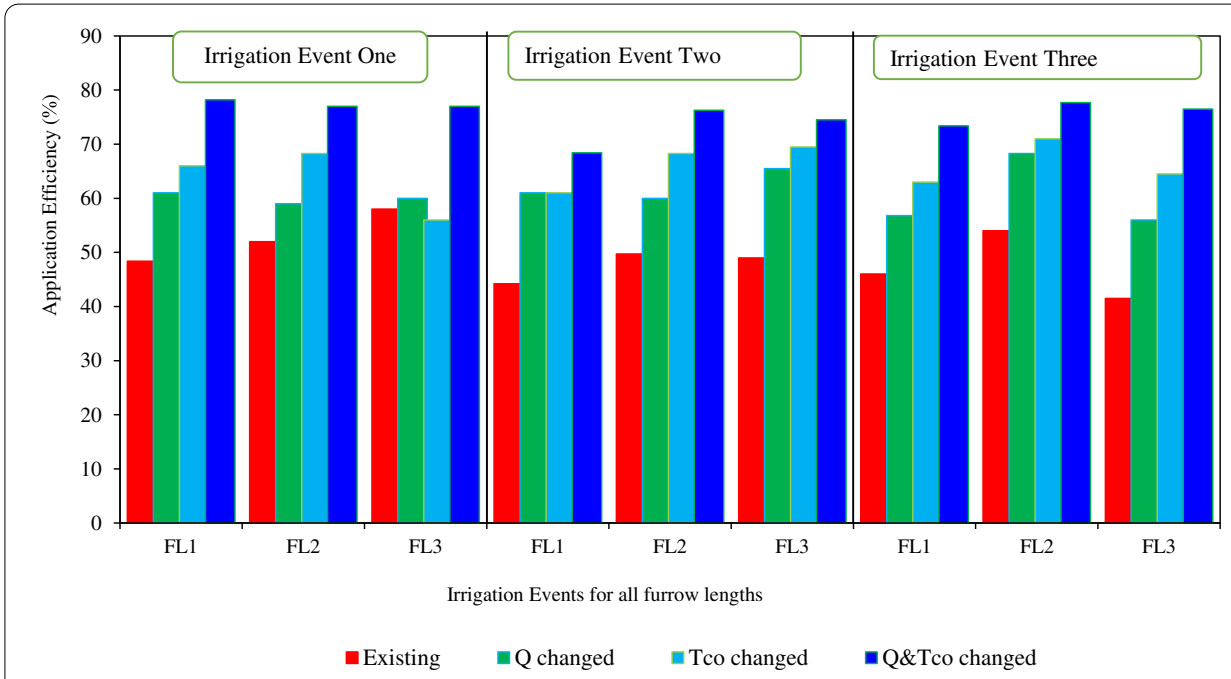

Fig. 2 Application efficiency performance of furrow irrigation

The current study findings were similar to the finding of Shumye and Singh [17] which revealed that the application efficiency of furrow irrigation is highly dependent on the decision variables, especially discharge applied in relation to the cutoff time which was within the recommended ranges. Similar to the current study, the other study findings by Mamo and Wolde [12] indicated that the application efficiency of furrow irrigation significantly changed as the discharge applied changed and less on the cutoff time. The findings by Taddesse et al. [18] also showed the application efficiency of furrow irrigation obtained by changing the decision variable was higher than the current study findings as well as other related findings. From the field observation during the current experiment, the main reasons which resulted in lower application efficiency were mismanagement of irrigation water, which includes the loss of irrigation water after entering into the field ditches due to lateral flow to the side furrows, time of irrigation application, and lack of soil consideration for irrigation since all soil types were irrigated similarly with a similar rate of application.

\section{Distribution uniformity}

The achievable distribution uniformity for furrow irrigation was poor if it is less than $70 \%$, good from 70 to $85 \%$, very good $85-90$, and excellent if greater than $90 \%$ [10]. As those authors conclude, distribution uniformity is poor and the irrigation water applied unevenly distributed if it is $\leq 60 \%$ and good if $\geq 80 \%$ which indicates that the applied is relatively uniform over the entire furrow length. Based on those, all furrow lengths were in the acceptable range during all irrigation events from both computed and simulated values. The highest and lowest computed distribution uniformity were 91 and 79.3\% from furrow lengths 64 and $48 \mathrm{~m}$ during the second and first irrigation events. When the average distribution uniformity from the three furrow lengths during all irrigation events was compared, better distribution uniformity was obtained from furrow length $64 \mathrm{~m}(91.0 \%)$ and less distribution uniformity obtained from furrow length $48 \mathrm{~m}(79.3 \%)$. This indicated that the irrigation water applied was uniformly distributed throughout 
the furrow length. When the computed values were simulated using the WinSRFR model, the maximum and minimum distribution uniformity were 91.0 and $79.3 \%$ from furrow lengths 32 and $64 \mathrm{~m}$ during the first and second irrigation events.

Unlike the application efficiency, the distribution uniformity of furrow irrigation was not improved after the decision variables were considered changed. From the simulated values using the WinSRFR model, the maximum and minimum distribution uniformity obtained were 82.2 and $62.5 \%$ from furrow lengths 32 and $64 \mathrm{~m}$ during the first and second irrigation events respectively. In general, by changing the decision variables, the distribution uniformity of furrow irrigation was not significantly improved, but after those data were simulated using the WinSRFR model, in almost all furrow lengths and irrigation events, it was reduced significantly. The distribution uniformity performance of furrow irrigation for all furrow lengths considered under the three irrigation events is presented in Fig. 3.

The study findings by [16]) indicate that the distribution uniformity of furrow irrigation was improved by changing inflow rate and cutoff time but the improvement was not significant as that of application efficiency similar to the current study results. The other study findings conducted by Mazarei et al. $[13,14]$ indicated that the minimum distribution uniformity was obtained during the low volume of irrigation applied to longer furrow length, but the distribution uniformity increased as the irrigation event increased but the current study result indicated that as the irrigation events increased, the distribution uniformity was not linearly increased.

\section{Deep percolation}

For properly designed and managed furrow irrigation, a deep percolation value ranges from 30 to $50 \%$, but as the values of deep percolation increased, it is not recommended since more irrigation water applied is lost (Griffiths, 2007). From the existing irrigation practices, the maximum and minimum computed deep percolation were 58.5 and $46.0 \%$ from furrow lengths 64 and $48 \mathrm{~m}$ during the third irrigation event.

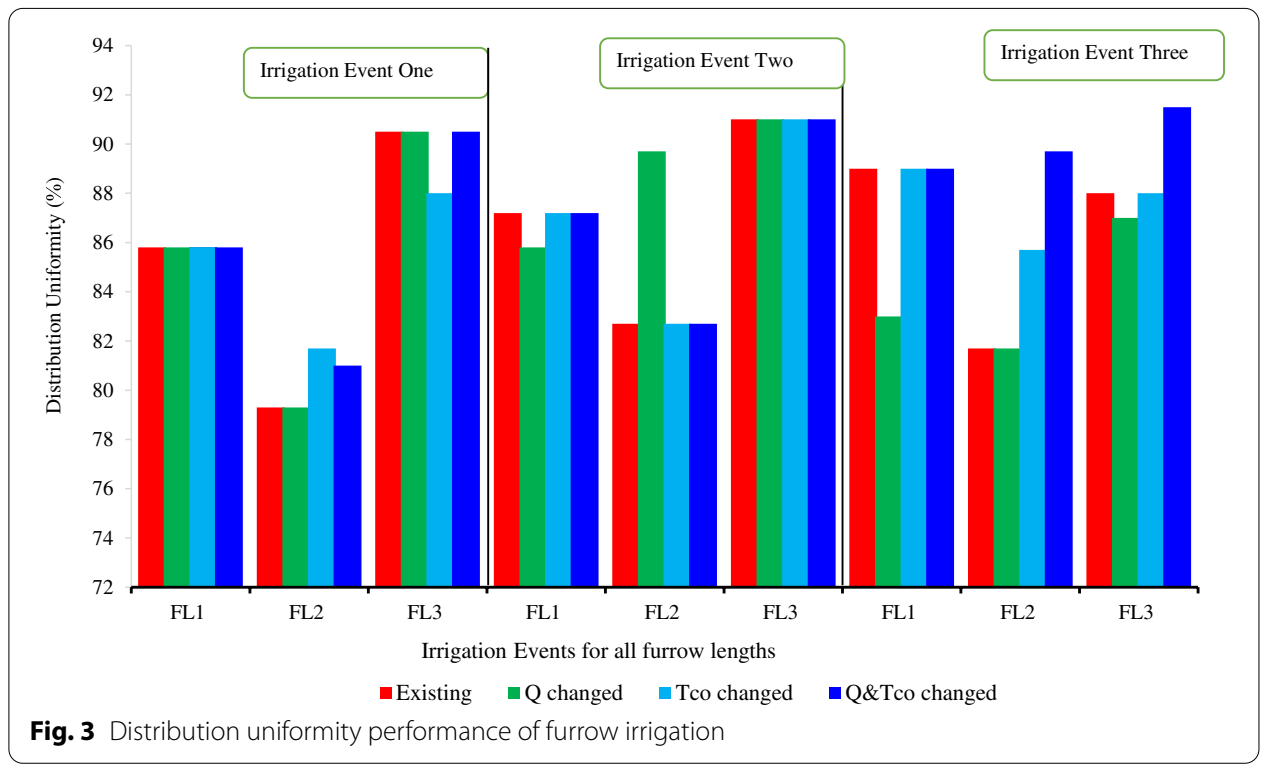


From the simulated values using the WinSRFR model, the maximum and minimum deep percolation obtained were 58.5 and $44.0 \%$ from furrow lengths 64 and $48 \mathrm{~m}$ during third and first irrigation events.

In the case of deep percolation, as the furrow irrigation decision variable changed, deep percolation of furrow irrigation was significantly improved similar to application efficiency. When the applied inflow rate was reduced, the computed maximum and minimum deep percolation obtained were 44 and $31.7 \%$ from furrow lengths 64 and $48 \mathrm{~m}$ during the third irrigation event. From the simulated values using the WinSRFR model, the maximum and minimum deep percolation obtained were 58 and $30.7 \%$ from furrow lengths 32 and $48 \mathrm{~m}$ during first and third irrigation events respectively.

When cutoff time changed by keeping the other variables constant, the computed maximum and minimum deep percolation obtained were 44.0 and $29.0 \%$ from furrow lengths 64 and $48 \mathrm{~m}$ during the first and third irrigation events. From the simulated values using the WinSRFR model, the maximum and minimum deep percolation obtained were 44.0 and $28.5 \%$ from furrow length 64 during the first and second irrigation events respectively. When both discharge and cutoff time changed by keeping the other variables constant, the computed maximum and minimum deep percolation obtained were 36.6 and $22.3 \%$ from furrow lengths 32 and $48 \mathrm{~m}$ during the third irrigation event. When this result was simulated using the WinSRFR model, the maximum and minimum deep percolation obtained were 37.8 and $21.5 \%$ from furrow lengths 32 and $64 \mathrm{~m}$ during the second irrigation event respectively. The deep percolation performance of furrow irrigation for all furrow lengths considered under the three irrigation events is presented in Fig. 4.

The study findings by Mazarei et al. [13, 14] indicated that the deep percolation was improved by changing the decision variables and the values were within the range of recommendation for furrow irrigation. But in the current study, the deep percolation was out of the recommendation ranges from the existing irrigation practices. However, similar to this study's findings, the current study also showed an improvement by changing the decision variables. The other study findings conducted by Mamo and Wolde [12]

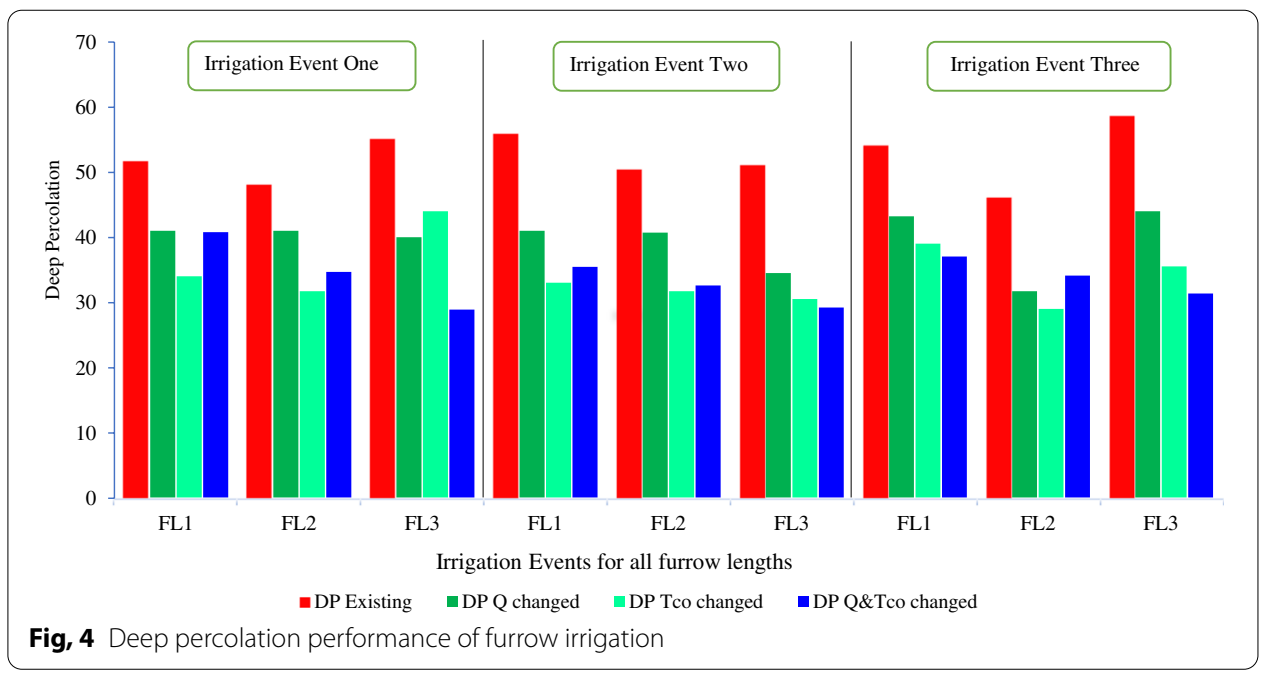


indicated that deep percolation was also within the acceptable range of all furrow lengths considered under the sugarcane field. Similar to this study, the current study result indicated that the computed values of deep percolation were within the acceptable range of all furrow lengths after the decision variables changed. Generally, from this study, it can be concluded that there was a high loss of irrigation water applied in the form of deep percolation for all furrow lengths based on the existing irrigation practices in the study area.

\section{Statistical analysis}

\section{Statistical analysis of advance and recession times}

Advance and recession times were measured and simulated under different furrow lengths $(32 \mathrm{~m}, 48 \mathrm{~m}$, and $64 \mathrm{~m})$ and uniform furrow slopes $(0.05 \%)$ for determining the possibility of using WinSRFR as a prediction tool of the furrow irrigation performance evaluation under the Wonji Shoa climatic condition.

Based on the values of indices obtained from advance time, in terms of $R^{2}$ measured values were better than the model for furrow length $32 \mathrm{~m}$ in all irrigation events. But for furrow lengths 48 and $64 \mathrm{~m}$, model predicted values were better than the measured values for all irrigation events. In terms of RMSE, the model predicted values were better than the measured values in all furrow lengths during all irrigation events (Table 8). In general, for all statistical indices considered for advance time, the model prediction was better than the measured values. This indicated that the time allocated for irrigation was not accurate as required for almost all furrow lengths during all irrigation events. From the current study result, it can be concluded that, the applied discharge and cutoff time should be reduced alternatively from the existing situation or increasing one decision variable and decreasing the other decision variable for all furrow lengths to obtain good performance efficiency of furrow irrigation. To attain the good performance of furrow irrigation, the applied discharge should be reduced from $4.7 \mathrm{l} / \mathrm{s}$ (currently applied inflow rate) to $3.5 \mathrm{l} / \mathrm{s}$, and the cut of time for each furrow should be increased from 9 to $11 \mathrm{~min}$ for furrow length $32 \mathrm{~m}$, from 15 to $18 \mathrm{~min}$ for furrow length $48 \mathrm{~m}$, and from 25 to 31

Table 8 Comparison of measured and simulated advance and recession times of the existing situation

\begin{tabular}{|c|c|c|c|c|c|c|c|c|c|}
\hline \multirow[t]{3}{*}{ IEs } & \multirow[t]{3}{*}{$\mathrm{FL}(\mathrm{m})$} & \multirow[t]{3}{*}{$Q(\mathrm{I} / \mathrm{s})$} & \multirow[t]{3}{*}{$T_{\mathrm{co}}(\mathrm{h})$} & \multicolumn{3}{|c|}{ Advanced } & \multicolumn{3}{|c|}{ Recession } \\
\hline & & & & \multicolumn{6}{|c|}{ Statistical indices } \\
\hline & & & & $R^{2}$ & RMSE & $d$ & $R^{2}$ & RMSE & $d$ \\
\hline \multirow[t]{3}{*}{1} & 32 & 4.7 & 9 & 0.01 & 2.00 & 0.83 & 1.00 & 0.02 & 0.99 \\
\hline & 48 & 4.7 & 15 & 0.97 & 0.06 & 0.32 & 0.75 & 0.30 & 0.99 \\
\hline & 64 & 4.7 & 25 & 1.00 & 0.00 & 0.99 & 1.00 & 0.00 & -0.88 \\
\hline \multirow[t]{3}{*}{2} & 32 & 4.7 & 9 & 0.01 & 4.02 & 0.79 & 0.81 & 0.00 & 0.99 \\
\hline & 48 & 4.7 & 15 & 0.97 & 0.06 & 0.68 & 0.96 & 0.17 & 0.99 \\
\hline & 64 & 4.7 & 25 & 1.00 & 0.00 & 0.99 & 1.00 & 0.00 & 0.91 \\
\hline \multirow[t]{3}{*}{3} & 32 & 4.7 & 10 & 0.01 & 0.00 & 0.41 & 0.89 & 0.00 & 0.99 \\
\hline & 48 & 4.7 & 15 & 0.99 & 0.06 & 0.98 & 0.84 & 0.21 & 0.99 \\
\hline & 64 & 4.7 & 25 & 1.00 & 0.00 & 0.99 & 1.00 & 0.00 & 0.99 \\
\hline
\end{tabular}

$R^{2}$ coefficient of determination, RMSE root mean square error, $d$ index of agreement 
min for furrow length $64 \mathrm{~m}$ under the current study area conditions. Because, due to the emerging problems of irrigation water shortage, it is better to increase cutoff time rather than increase inflow rate to obtain a good performance of irrigation.

\section{Statistical analysis of furrow irrigation performance}

The performance of existing furrow irrigation was evaluated using selected statistical indices. Those statistical indices were used to evaluate whether the measured performance of the furrow irrigation was in a good agreement with the simulated values or not. To obtain the improved performance of furrow irrigation, the decision variables (discharge and cutoff time) were changed alternatively from the existing irrigation practices. The computed performance from actually measured data during three irrigation events for all furrow lengths considered $(32,48$, and $64 \mathrm{~m})$ was simulated using the WinSRFR model.

There was a poor agreement between measured and simulated values of furrow irrigation for almost all irrigation events for furrow lengths 32 and $64 \mathrm{~m}$ but there was relatively a better agreement for furrow length $48 \mathrm{~m}$ in terms of all statistical indices (Table 9). In the case of all the furrow irrigation performances considered, the model prediction was better than the computed values for all furrow lengths in all irrigation events. This indicated that more irrigation water applied was lost before the crop uses; irrigation water applied was not uniformly distributed throughout the furrow lengths in all irrigation events for all furrow lengths considered in which more of the irrigation water losses was due to deep percolation since the furrow condition close-ended. But, after the decision variables were changed, the performance of furrow irrigation was significantly improved. All the statistical indices used to evaluate the goodness of fit between the measured and simulated values also showed good agreements in all furrow lengths during all irrigation events (Table 10).

The study findings by Dewedar et al. [5] revealed that with the indices used to evaluate the performance of furrow irrigation with different furrow length results, the model predictions were better than the computed value similar to the current study based on the existing irrigation practices. The other study findings by Taddesse et al. [18] indicated that the performance of furrow irrigation predicted by the model was better than

Table 9 Statistical indices of existing furrow irrigation performances

\begin{tabular}{|c|c|c|c|c|c|c|c|c|c|c|}
\hline \multirow[t]{2}{*}{ IEs } & \multirow[t]{2}{*}{$\mathrm{FL}(\mathrm{m})$} & \multicolumn{3}{|l|}{$\mathrm{AE}$} & \multicolumn{3}{|l|}{ DU } & \multicolumn{3}{|l|}{$\mathrm{DP}$} \\
\hline & & $R^{2}$ & RMSE & $d$ & $R^{2}$ & RMSE & $d$ & $R^{2}$ & RMSE & $d$ \\
\hline \multirow[t]{3}{*}{1} & 32 & 0.57 & 6.68 & 0.99 & 1.00 & 6.32 & 1.00 & 0.57 & 6.68 & 0.99 \\
\hline & 48 & 1.00 & 0.17 & -8.46 & 0.71 & 4.77 & 0.15 & 0.08 & 2.01 & 0.79 \\
\hline & 64 & 0.50 & 2.50 & 0.83 & 0.82 & 15.01 & 0.83 & 1.00 & 11.00 & 0.85 \\
\hline \multirow[t]{3}{*}{2} & 32 & 0.55 & 2.83 & 1.00 & 1.00 & 6.32 & 0.99 & 1.00 & 2.83 & 1.00 \\
\hline & 48 & 0.67 & 1.37 & 0.99 & 0.98 & 11.67 & 0.97 & 0.38 & 0.69 & 1.00 \\
\hline & 64 & 0.50 & 2.00 & 1.00 & 1.00 & 2.40 & 0.95 & 1.00 & 0.00 & 1.00 \\
\hline \multirow[t]{3}{*}{3} & 32 & 1.00 & 0.40 & 0.99 & 0.95 & 8.67 & 0.99 & 1.00 & 7.40 & 0.99 \\
\hline & 48 & 1.00 & 0.33 & 1.00 & 0.74 & 8.96 & -6.12 & 1.00 & 0.33 & 1.00 \\
\hline & 64 & 1.00 & 0.00 & 1.00 & 0.50 & 13.65 & 0.85 & 1.00 & 0.00 & 1.00 \\
\hline
\end{tabular}


Table 10 Statistical indices of improved furrow irrigation performances

\begin{tabular}{|c|c|c|c|c|c|c|c|c|c|c|}
\hline \multirow[t]{3}{*}{ IEs } & \multirow[t]{3}{*}{$\mathrm{FL}$} & \multicolumn{3}{|l|}{$\mathrm{AE}$} & \multicolumn{3}{|l|}{ DU } & \multicolumn{3}{|l|}{$\mathrm{DP}$} \\
\hline & & \multicolumn{9}{|c|}{ Statistical indices } \\
\hline & & $\overline{R^{2}}$ & RMSE & $d$ & $R^{2}$ & RMSE & $d$ & $R^{2}$ & RMSE & $d$ \\
\hline \multirow[t]{3}{*}{1} & 32 & 0.72 & 0.62 & 0.62 & 0.26 & 0.86 & 0.41 & 0.80 & 0.15 & 0.89 \\
\hline & 48 & 0.99 & 0.41 & 0.05 & 0.97 & 0.99 & 0.71 & 0.66 & 2.09 & 0.92 \\
\hline & 64 & 1.00 & 0.00 & 0.00 & 1.00 & 0.00 & 1.00 & 0.23 & 4.19 & 0.92 \\
\hline \multirow[t]{3}{*}{2} & 32 & 0.31 & 0.18 & 0.18 & 0.56 & 0.95 & 0.41 & 0.80 & 0.15 & 0.89 \\
\hline & 48 & 0.99 & 0.57 & 0.09 & 0.98 & 0.69 & 0.83 & 0.55 & 0.47 & 1.00 \\
\hline & 64 & 1.00 & 0.00 & 0.00 & 1.00 & 0.00 & 1.00 & 0.56 & 0.38 & 0.80 \\
\hline \multirow[t]{3}{*}{3} & 32 & 0.30 & 0.79 & 0.49 & 0.98 & 0.83 & 0.11 & 0.23 & 0.25 & 0.76 \\
\hline & 48 & 0.99 & 0.61 & 0.02 & 0.99 & 0.97 & 0.74 & 0.51 & 1.18 & 1.00 \\
\hline & 64 & 1.00 & 0.00 & 1.00 & 1.00 & 0.00 & 1.00 & 0.30 & 2.23 & 0.90 \\
\hline
\end{tabular}

the computed values which showed the goodness of fit between computed and predicted was not good similar to the current study under the existing situations.

\section{Conclusions}

Performance evaluation of furrow irrigation under the Wonji Shoa sugarcane plantation is important since it is the dominant irrigation system for sugarcane production for a long period of time. The irrigation performance indicators considered in this study were application efficiency, distribution uniformity, and deep percolation. In this study, to improve the performance of furrow irrigation under the sugarcane field, the decision variables which significantly influence the efficiency (inflow rate and cutoff time) were changed alternative to improve the performance of the furrow irrigation from existing irrigation practices. The inflow rate was reduced by keeping the other decision variables contestant and the performance of furrow irrigation was improved. Also, as another option, the irrigation cutoff time was increased by 2, 3, and 6 min for furrow lengths 32,48 , and $64 \mathrm{~m}$ respectively by keeping the other variables constant; again, the performances of furrow irrigation was significantly improved. As another improvement option, both the inflow rate and cutoff time changes were combined together that resulted in a better performance of the furrow irrigation as compared to the existing irrigation. From the irrigation performance indicators considered, application efficiency and deep percolation were significantly improved by changing inflow rate cutoff time as compared to the existing irrigation practices for all furrow lengths during all irrigation events but distribution uniformity was not significantly changed. In general, the application efficiency and deep percolation losses were significantly improved, while the distribution uniformity was not changed from the existing irrigation practices.

The performance of furrow irrigation was optimized by changing the discharge and cutoff time for all furrow lengths during all irrigation events. This result indicated that, the inflow rate of $3.5 \mathrm{l} / \mathrm{s}$ showed better furrow irrigation performance than the existing inflow rate of $4.7 \mathrm{l} / \mathrm{s}$ with respect to the cutoff time changed for each furrow length. The measured data were simulated using the WinSRFR model for each decision variable, and similarly, the better improvements of the furrow irrigation performances were obtained at the same altered decision variables for all furrow lengths. Therefore, from the current 
findings, it can be concluded that to improve the irrigation performance, inflow rate should be reduced by increasing a little bit irrigation cutoff time for all furrow lengths under the current study area. Also, furrow length $48 \mathrm{~m}$ showed better improvements as compared to 32 and $64 \mathrm{~m}$. The result of these findings can be used in similar situations with the current study area. Finally, it is strictly recommended to reconsider and adjust inflow rate and irrigation cutoff time to improve the irrigation performances and reduce the loss of irrigation water.

\section{Abbreviations}

AE: Application efficiency; $d$ : Index of agreement; DP: Deep percolation; DU: Distribution uniformity; MARC: Melkassa Agricultural Research Center; OP: Optimization performance; $R^{2}$ : Coefficient of determination; RMSE: Root mean square error; WSSE: Wonji Shoa Sugar Estate.

\section{Acknowledgements}

We are grateful to Adama Science and Technology and Ambo University for the financial support for this research. We would like to appreciate the Melkassa Agricultural Research Center (MARC), especially the irrigation and drainage department, since they provided some materials required for data collection during this research. We also thank Mr. Demissie Tsegawu and Mr. Mengistu Bossie for their support by providing the transport facilities during data collection. Finally, we thank Sugar Corporation Research and Development at the Wonji Center for their collaboration during laboratory analysis throughout the research works undertaken.

\section{Authors' contributions}

All authors played a vital role to accomplish this manuscript. The corresponding author, BY, developed the research idea, designed the research method, and collected all required data on furrow geometry, soil data, advance, cutoff, and recession time, and analyze the collected data. After all data were collected and arranged, required soil parameters were analyzed, the performance evaluation of furrow irrigation using WinSRFR model computed and simulated, and finally, the manuscript was organized and written. MA evaluated the overall work of the research starting from developing the idea of the research, critically commenting, editing the manuscript, and improving the scientific write-up of the manuscript. MY and TH have contributed consistent and inspiring guidance and valuable suggestions on the manuscript of the corresponding author. Finally, all the authors have read and approved the manuscript as correct and as to the standard for publication.

\section{Funding}

There is no fund obtained for the research conducted and I think I indicated this in the submission process at the end before approving the submission.

\section{Availability of data and materials}

All the raw data from where the analysis was done in the manuscript are available from the corresponding author. At any time with the reasonable requirements, the corresponding author can be contacted.

\section{Declarations}

\section{Competing interests}

The authors declare that they have no conflict of interest regarding the publication of this article.

\section{Author details}

${ }^{1}$ Department of Water Resource Engineering, Adama Science and Technology University, Adama, Ethiopia. ${ }^{2}$ Arizona State University, Tempe, USA. ${ }^{3}$ Ethiopian Institute of Ethiopian Agricultural Research, Melkassa, Ethiopia.

Received: 9 August 2021 Accepted: 22 January 2022

Published online: 13 February 2022

\section{References}

1. Akbar G, Ahmad MM, Ghafoor A, Khan M, Islam Z (2016) Irrigation efficiencies potential under surface irrigated. J Engineering Appl Sci 35(2):15-24

2. Akbar G, Raine $S, M c H u g h ~ A D$, Hamilton G, Hussain Q (2017) Strategies to improve the irrigation efficiency of raised beds on small farms. Sarhad J Agriculture 33(4):615-623. https://doi.org/10.17582/journal.sja/2017/33.4. 615.623

3. Ali OAM, Mohammed ASH (2015) Performance evaluation of gated pipes technique for improving surface irrigation efficiency in maize hybrids. Agricultural Sciences 06(05):550-570. https://doi.org/10.4236/as.2015.65055

4. Bashour, I. I., and Sayegh, A. H. (2007). Methods of Analysis for soils of arid and semi-arid regions. Food and Agriculture Organisation of the United Nations, 128.

5. Dewedar, O. M., Mehanna, H. M. and El-shafie, A. F. (2019). Validation of Winsrff For some hydraulic parameters of furrow irrigation in Egypt. 19(1), 2108-2115. 
6. Ebrahimian $\mathrm{H}$, Liaghat $\mathrm{A}$ (2011) Field evaluation of various mathematical models for furrow and border irrigation systems. Soil Water Res 6(2):91-101 https://doi.org/10.17221/34/2010-swr

7. El-Hazek A (2016) Challenges for optimum design of surface irrigation systems. Journal of Scientific Research and Reports 11(6):1-9. https://doi.org/10.9734/jsrr/2016/27504

8. FAO (Food and Agricultural Organization of the United Nations). (2020). Soil testing methods manual. In Soil testing methods manual. https://doi.org/10.4060/ca2796en

9. Haile GG, Kassa AK (2015) Irrigation in Ethiopia, a review. J Environment Earth Sci 3(10):264-269

10. Irmak S, Odhiambo LO, Kranz WL, Eisenhauer DE (2011) Irrigation efficiency, uniformity and crop water use efficiency. Biological Syst Engineering:1-10

11. Koech $R$, Langat $P$ (2018) Improving irrigation water use efficiency: a review of advances, challenges and opportunities in the Australian context. Water (Switzerland) 10(12). https://doi.org/10.3390/w10121771

12. Mamo Y, Wolde $Z$ (2015) Evaluation of water management in irrigated sugarcane production : case study of Wondogenet, Snnpr, description of study area. Global Adv Res J Phys Appl Sci 4(1):57-63

13. Mazarei R, Mohammadi AS, Naseri AA, Ebrahimian H, Izadpanah Z (2020a) Optimization of furrow irrigation performance of sugarcane fields based on inflow and geometric parameters using WinSRFR in Southwest of Iran. Agricultural Water Manag 228(November):105899. https://doi.org/10.1016/j.agwat.2019.105899

14. Mazarei R, Soltani A, Ali A, Ebrahimian H (2020b) Optimization of furrow irrigation performance of sugarcane fields based on inflow and geometric parameters using WinSRFR in Southwest of Iran. Agricultural Water Management 228(November 2019):105899 https://doi.org/10.1016/j.agwat.2019.105899

15. Nie WB, Fei $\sqcup$, Ma XY (2014) Applied closed-end furrow irrigation optimized design based on field and simulated advance data. J Agricultural Sci Technology 16(2):395-408

16. Pascual-Seva N, Bautista AS, Lopez-Galarza S, Maroto JV, Pascual B (2013) Performance analysis and optimization of furrow-rrigated chufa crops in Valencia (Spain). Spanish J Agricultural Res 11(1):268-278. https://doi.org/10.5424/ sjar/2013111-3384

17. Shumye A, Singh IP (2018) Evaluation of canal water conveyance and on-farm water application for a small-scale irrigation scheme in Ethiopia. Int J Water Resources Environmental Engineering 10(8):100-110. https://doi.org/10. 5897/JWWREE2018.0800

18. Taddesse F, Bekele M, Tadele D (2019) Evaluation of hydraulic performance : a case study of etana small scale irrigation scheme : wolaita zone. Ethiopia. International Journal Hydrology 3(5):369-374 https://doi.org/10.15406/ijh. 2019.03.00202

19. Tesfaye tefera yigezu, Kannan Narayanan and Tilahun Hordof. (2016) Effect of Furrow Length and Flow Rate on Irrigation Performances and Yield of Maize. Int J Engineering Res Technology (IJERT) 5(04):602-607 https://doi.org/ 10.17577/ijertv5is040846

20. Valipour, M. (2012). Comparison of surface irrigation simulation models: full hydrodynamic, zero inertia, kinematic wave. J Agricultural Sci, 4(12). https://doi.org/https://doi.org/10.5539/jas.v4n12p68

21. Zayton AM, Eng A, Inst R (2015) Predicting Of Infiltration Parameters Under Different Inflow Rates. Egypt. J. Agric. Res. 93(1):163-184

\section{Publisher's Note}

Springer Nature remains neutral with regard to jurisdictional claims in published maps and institutional affiliations.

\section{Submit your manuscript to a SpringerOpen ${ }^{\circ}$ journal and benefit from:}

- Convenient online submission

- Rigorous peer review

- Open access: articles freely available online

- High visibility within the field

- Retaining the copyright to your article

Submit your next manuscript at $\mathbf{s p r i n g e r o p e n . c o m ~}$ 